\title{
LA ARQUEOLOGÍA INDUSTRIAL EN LEÓN. REFLEXIONES A PARTIR DE LA INVESTIGACIÓN EN EL VAL DE SAN LORENZO
}

\author{
Pablo AlONSO GONZÁLEZ
}

\begin{abstract}
RESUMEN: La Arqueología Industrial es una disciplina relativamente joven cuyas bases teóricas y prácticas se encuentran en continua discusión y renovación. Con el presente artículo tratamos de hacer alguna aportación al debate y mostrar, a la vez que reivindicar, la deficitaria situación de la provincia de León en cuanto al cuidado de este Patrimonio y la realización de estudios arqueológicos. Partimos del trabajo realizado en el Val de San Lorenzo, un pueblo que vivió un gran auge de su industria textil y ahora se enfrenta a la decadencia..

PALABRAS CLAVE: Arqueología Industrial, Puesta en valor, Patrimonio textil.

ABSTRACT: Industrial Archaeology is a relatively young discipline whose theoretical and practical bases are in continuous discussion and renovation. With the present article we dealt to make some contribution to the debate and to show, simultaneously that to vindicate, the deficit situation of the province of Leon as far as the care of this Patrimony and the accomplishment of archaeological studies. We left from the work made in the Val of San Lorenzo, a town that lived a great height on its textile industry and now it faces the decay.
\end{abstract}

KEYWORDS: Industrial Archaeology, Enhancement Strategy, Textile Heritage.

\section{INTRODUCCIÓN.}

Los objetivos del artículo que nos ocupa son varios. Por un lado queremos mostrar sucintamente el estado de la cuestión de la Arqueología Industrial en León, intentando poner de manifiesto las amplias posibilidades que nuestro patrimonio ofrece. Expondremos los resultados de nuestra investigación en el Val de San Lorenzo como un posible ejemplo de los diversos modos de estudiar y poner en valor este patrimonio. Finalmente plasmaremos algunas de las reflexiones que la elaboración de este análisis nos ha planteado en lo referente a la teoría y práctica de la Arqueología Industrial. 
Convencidos siempre del valor de esta disciplina para el estudio y salvaguarda de un patrimonio del que cada vez queda menos, para ponerla al servicio de una sociedad que no duda en calificarse de posmoderna.

Este carácter posmoderno, escudriñando desde las alturas, mira a su pasado y se ve a sí mismo como una culminación de la historia. ${ }^{1}$ Desde ese punto de observación privilegiado busca conocer y conservar todos y cada uno de los peldaños que le llevaron a ese ocaso. Es lo que Nietzsche llamaría una sociedad con un "exceso de historia". ${ }^{2}$ Gran Bretaña sería un ejemplo particularmente claro; el resto de las naciones europeas siguen, de uno u otro modo, su camino.

Este paradigma - cuyo foco de irradiación gemelo se halla en EEUU- lleva consigo una gran valoración del patrimonio en todos sus niveles, y, en lo que nos toca, del Industrial.

En relación con esta circunstancia, algunos han llegado a decir que la fiebre conservacionista de este tipo de patrimonio es una búsqueda del capitalismo de enraizarse en sí mismo ${ }^{3}$, en clara contraposición al estudio marxista de la cultura material y la búsqueda de los orígenes de la desigualdad.

Sea como fuere, en España debemos estar preparados para adecuarnos a nuevos preceptos teóricos y a la aparición y uso de nuevas herramientas para el tratamiento de estas cuestiones desde la arqueología.

Conviene, por tanto, ponerse en marcha y dar a conocer experiencias de Arqueología Industrial. Y es que en Arqueología la teoría surge en gran parte al enfrentarse con la práctica cotidiana, sus problemas y sus heterogéneas vicisitudes.

\section{LA ARQUEOLOGÍA INDUSTRIAL EN LEÓN}

Podríamos decir sin miedo a equivocarnos que en nuestra provincia la Arqueología Industrial es una disciplina totalmente desconocida para el gran público y de poca difusión en el ámbito científico. Desde la Universidad la iniciativa más interesante es la emprendida desde la Geografía a través del grupo "Investigaciones sobre el territorio" que ya cuenta con una importante tradición y resultados positivos. Sin embargo, nuestro enfoque va más dirigido al estudio

${ }^{1}$ FukuYama, F. (1992) El fin de la Historia y el último hombre. México, Planeta.

2 NiETzsche, F. (2006) Segunda consideración intempestiva. Buenos Aires, Libros del Zorzal.

3 CAstro Morales, F. (2001) "Memoria, ocio y cultura: nuevos usos en España para el patrimonio industrial" Preservación de la Arquitectura Industrial en Iberoamérica y España, Instituto Andaluz del Patrimonio Histórico. pp. 204-212. 
arqueológico de paisajes industriales que al análisis de reutilizaciones destacadas o específicas como las que este grupo estudia a nivel regional. ${ }^{4}$ Encontramos también estudios históricos como el de José Andrés González ${ }^{5}$ en La Robla, que muestran el potencial de los archivos para el estudio de los remanentes industriales, confiriéndole quizás excesiva importancia. No creemos que los datos de archivo nos permitan per se llevar a cabo un inventario riguroso; para empezar, el estado de conservación de una industria abandonada no puede provenir de una labor de archivo, que resulta, por otra parte, indispensable. Otro ejemplo interesante es el de José Luis López en Astorga, ${ }^{6}$ que indaga en el pasado de los diversos sectores industriales de la ciudad. Igualmente desde el punto de vista de la ingeniería encontramos trabajos, como los emprendidos en Sabero. ${ }^{7}$ A nivel provincial y de la región berciana son indispensables los trabajos de Balboa de Paz. ${ }^{8}$

Algunos análisis son realizados por estudiosos y curiosos a nivel local, cuyos trabajos son sin duda valiosísimos, pero en ocasiones carecen de la proyección científica que una disciplina que se tilda de arqueológica exige.

Es necesaria la elaboración de trabajos que busquen una concienciación social respecto al valor de este patrimonio. Un patrimonio abundantísimo y mayoritariamente desprotegido. Mientras Asturias pone en valor su patrimonio minero, estudiándolo y difundiéndolo a través de publicaciones y museos, en León las zonas mineras se abandonan y olvidan por lo general. Ejemplo de ello es toda la zona minera norteña que linda con Asturias, zonas del Bierzo o La Cabrera. Ya desde 1975 The International Committee for the Conservation of Industrial Heritage cuenta con una sección dedicada a la minería, y en Noviembre de 1999 se

4 LÓPEZ GONZÁlez, A. (2006) "Notas sobre el grupo "Investigaciones sobre el territorio" del Departamento de Geografía de la Universidad de León" Revista bibliográfica de Geografía y Ciencias Sociales. Vol XI, no 694. <http://www.ub.es/geocrit/b3w-694.htm>

${ }^{5}$ GonzÁlez Pedraza, J. A. (2000) "El Pozo Ibarra a través de los documentos del Archivo de Sociedad". Anónima Hullera Vasco-Leonesa: fuentes para su estudio" Actas de las II Jornadas Internacionales sobre el Patrimonio Industrial (INCUNA (Asociación de Arqueología Industrial), Gijón, 4-7 de mayo de 2000) Gijón, IncunA, p. 245-251.

${ }^{6}$ López DíAz, J.L., (1991) Ayer y hoy del comercio y la industria en Astorga, Astorga, Cámara Oficial de Comercio e Industria de Astorga.

${ }^{7}$ Celemín Matachana, M. y Martínez Rodríguez, A. (1997) "Recuperación económica de cuencas mineras y Arqueología Industrial. El caso de Sabero, León/España” Informes de la Construcción. vol. 49.

${ }^{8}$ BAlboa de PAZ, J.A., (2006) El patrimonio Industrial de la provincia de León León, Instituto Leonés de Cultura. 
funda la European Federation of Associations of Industrials and Technical Heritage (E-FAITH) que también presta atención a asuntos mineros. ${ }^{9}$

Asturias también posee una asociación de Arqueología Industrial (INCUNA) que estudia, hace publicaciones y protege el Patrimonio, y esto por no hablar ya de los casos de País Vasco o Cataluña, mucho más avanzados. En León nada de esto tiene ni siquiera visos de acontecer.

Y en entornos urbanos la situación no es mucho mejor. El crecimiento irreflexivo y la especulación son predadores naturales de unas presas suculentas y desprotegidas que suelen ocupar amplias superficies de suelo en la periferia de la ciudad. Proyectos integradores como el de la azucarera de León en el futuro palacio de congresos son la excepción que confirma la regla. Otros dos proyectos destacan en la provincia:

- La conversión de la Antigua central térmica de la Minero Siderúrgica de Ponferrada -MSP-., en Museo Nacional de la Energía. ${ }^{10}$

- La no poco problemática reutilización de la Ferrería de San Blas en Sabero como museo de la minería.

Abandono y destrucción no son las únicas formas de pérdida de nuestros remanentes. En la Maragatería los museos catalanes compran a precios irrisorios telares mecánicos seculares a veces únicos en la península.

En los últimos tiempos se ha venido estudiando y revalorizando cada vez más tanto el pasado prerromano como el Reino de León por diversas razones; ¿por qué dejar de lado entonces un periodo en el que la provincia estuvo en auge, alcanzando la máxima expansión demográfica de su historia y un gran dinamismo económico?

Reclamamos a las instituciones provinciales y regionales la necesidad de un inventario similar al que se hizo en el País Vasco entre 1990-1994. ${ }^{11}$ Para poder

9 Carvajal, D. J., GonzÁlez, A. Mining heritage \& closure mines Grupo de Hidrogeología y Medio Ambiente. Escuela Politécnica Superior. Campus de La Rábida, Universidad de Huelva. $<\mathrm{http}: / / 200.20 .105 .7 / \mathrm{imaac} /$ publications/proceedings/Cierre_de_minas/patrimonio\%20Minero\%20y2 $0 \%$ cierre $\% 20$ minas.doc $>$

${ }^{10}$ LÓPEZ GONZÁLEZ, A. (2006) "Notas sobre el grupo "Investigaciones sobre el territorio" del Departamento de Geografía de la Universidad de León" Revista bibliográfica de Geografía y Ciencias Sociales. Vol XI, no 694. <http://www.ub.es/geocrit/b3w-694.htm> 
llevar a cabo una gestión óptima del patrimonio es necesario, en primer lugar, saber lo que tenemos entre manos. Después, los condicionantes económicos pueden imponer una vía u otra: o primero estudiar y después poner en valor, o viceversa; o simplemente una de ambas. Posteriormente, las posibilidades son infinitas: reutilizaciones, musealizaciones, ecomuseos y paisajes culturales.

Cualquiera de los caminos que escojamos supondrá una mejoría de la situación actual. La Ciencia sólo se encarga de conocer y buscar las causas y consecuencias, está más allá del bien y del mal, es amoral. Sólo la sociedad, a través de la tecnología y sus aplicaciones, escoge cual es el camino que quiere seguir. Somos, por tanto, responsables de nuestro presente y de qué recuerdo del pasado queremos inmortalizar para el futuro.

\section{EL VAL DE SAN LORENZO}

Al enfrentarnos al análisis de este acogedor pueblo maragato realizamos un proyecto "ideal" muy ambicioso, conscientes de nuestra incapacidad para completarlo por falta de tiempo - se trataba de un trabajo para la asignatura Arqueología Industrial de la Universidad de Córdoba-. Procuramos trazar unas líneas básicas que permitiesen en el futuro un estudio exhaustivo y que, a la vez, se presentasen extensibles a pueblos de las características del Val de San Lorenzo dentro de la misma provincia de León especializados en alguna actividad tradicional que esté en vías de desaparición. Así por ejemplo Jiménez de Jamuz con la cerámica, y algún otro con cesterías, pieles, etc.

Los objetivos, al igual que el trabajo, seguían dos sendas divergentes: por un lado, conocer la historia contemporánea del pueblo y sus habitantes con especial atención a su industria primordial, el textil. Por otro, indagar en las causas que han provocado su decadencia como centro productivo, buscando posibles salidas a la misma.

Para la consecución de estos objetivos, planteamos un equipo ideal compuesto por un arqueólogo y un ingeniero industrial, con la posibilidad de contar con informático y arquitecto.

Debería llevarse a cabo un vaciado bibliográfico y documental, tanto en el archivo municipal como en archivos de empresa, una especial atención a los datos orales y un análisis arqueológico tanto del pueblo en sí como de su entorno.

11 IbÁÑEZ, M. Y ZABALA, M. (2003) Ponencia de Patrimonio Industrial A.V.P.I.O.P. $<$ http://www.avpiop.com/cas/files/Publicaciones\%20de\%20la\%20AVPIOP/Otras\%20Publicaciones/P onencia\%20Plan\%20Vasco\%20de\%20la\%20Cultura\%20(2003).pdf > 
Para comprender el proceso principal - el auge y decadencia del textil- creímos necesario abarcar otra serie de subprocesos que deberían ser comprendidos después del estudio del hábitat y de la historia del pueblo:

- El cambio que produjo la llegada del maquinismo, a todos los niveles: relación con la tierra, el papel de la mujer y la familia, las condiciones de trabajo, etc.

- La aparición de nuevas expresiones sociales

- La obtención de recursos y las herramientas.

- El sector textil a nivel nacional e internacional.

- Las mentalidades: producto natural y/o tradicional.

- El pueblo en la actualidad: capacidad de recuperación.

- Las transformaciones en el paisaje.

A partir de la comprensión de estas variantes, elaborar:

- Un inventario industrial, que nos ayude a conocer el pasado del pueblo a la vez que permite valorar el potencial base para una posible puesta en marcha de rehabilitaciones con fines museísticos o de puesta en valor.

- Un completo mapa digital que se colgaría en la Red y que serviría como atractivo para los curiosos. En él figurarían los diversos productores textiles con sus productos y precios, rutas arqueológicas o de senderismo, museos, antiguas fábricas, puntos de interés, etc.

\section{GEOGRAFÍA E HISTORIA}

El Val de San Lorenzo se sitúa en la comarca leonesa de la Maragatería, a 7Km de Astorga. En él realizamos un estudio sobre climatología, flora y fauna y edafología, del que prescindiremos aquí. Cabe decir que su altitud, - cerca de 1000 metros - su clima exigente y la proximidad del suelo a la roca madre, hacen que su capacidad productiva agropecuaria sea mínima.

Demográficamente, su peso es importante en comparación con otros núcleos de la zona. Cuenta en la actualidad con unos 750 habitantes, pese a haber alcanzado en sus momentos de máximo esplendor -hacia 1850- los 2500. Aún así, consideramos que ha superado relativamente bien el proceso de despoblación rural gracias a su industrialización. 
Pese que el estudio del hábitat no era un hecho central en la investigación, podemos trazar unas líneas evolutivas generales. En primer lugar encontramos en una elevación al NO del pueblo un antiguo castro, aparentemente de morfología romana, aunque sólo una excavación nos sacaría de dudas respecto a su adscripción cultural original. Posteriormente - época tardorromana o alta edad media - la población se traslada al valle, momento en el cual recibiría el nombre de "San Lorenzo". Posteriormente - siglos XII-XIII- comienza a denominársele como "Val de San Lorenzo", en clara referencia a su emplazamiento en un valle. Sin embargo, en cierto momento, el poblamiento se traslada de nuevo al alto, en torno a la ermita, quedándonos diversos vestigios de la anterior ocupación en los alrededores de la iglesia.

Los escasos rendimientos de la zona obligaban a sus habitantes a desarrollar otras actividades para su supervivencia. Si en el resto de la Maragatería se lanzaron a la arriería, en Val de San Lorenzo la dedicación fue preferentemente textil. Este dinamismo se documenta ya en el siglo XVII aunque seguramente se iniciase antes. $^{12}$

El sistema de producción textil tradicional se mantuvo hasta 1856-57, con la crisis textil nacional. La modernización se produce gracias a la acción de José Cordero, quien trabaja en Palencia y trae al Val nuevos modelos productivos. ${ }^{13}$

A partir de este momento se produce un incesante incremento de la producción que culmina en 1919 con la creación de "La Unión del Gremio de Fabricantes", momento en el cual podemos hablar del inicio de la producción moderna. ${ }^{14} \mathrm{Si}$ bien en un inicio los productores se agruparon en este gremio, la importante demanda llevó a la implantación de diversos centros productivos individuales que crecieron paulatinamente hasta la crisis de los años 80 . Una crisis de la que todavía no se ha conseguido escapar.

Los rasgos de este crecimiento son interesantes, ya que nos hablan de una evolución a diversos ritmos; por un lado se mantiene la producción artesanal tradicional y por otro existe una industria textil moderna. Entre ambos sistemas

12 RUBIO PÉREZ, L. M. (1995) La burguesía maragata: dimensión social, comercio y capital en la Corona de Castilla durante la Edad Moderna León, Secretariado de Publicaciones Universidad de León.

13 García, E. (1900) Notas autobiográficas de José Cordero Museo Textil del Val de San Lorenzo.

14 García Escudero, R., (1953) Por tierras maragatas Astorga, Ind. Tip. Cornejo. 
podemos hallar todas las fases posibles $\mathrm{y}$, por lo tanto, una gran diversidad tipológica de edificios para albergar estas actividades.

El estudio de la maquinaria muestra cómo la mayor parte procede de Cataluña, comprada de segunda mano. De hecho, algunas de estas reliquias ya ha ido a parar a museos catalanes. Otras se conservan en el museo del pueblo, dividido en dos centros que reutilizan instalaciones productivas y activo desde hace ya más de diez años.

Las materias primas utilizadas y sus formas de trabajo han sido estudiadas e individualizadas. Los molinos de linaza en desuso muestran cómo en inicio el lino fue una materia clave, siendo poco a poco sustituida por la lana. En un principio se compraba la autóctona, pero rápidamente surgió la necesidad de importar: primero de Sanabria-Aliste, pasando a la zona de Tierra de Campos para en las últimas décadas adquirirla de Galicia, Extremadura o Tierra de Campos.

Mención aparte merece la industria tintórea que surgió paralelamente al crecimiento textil.

\section{EL CAMBIO SOCIAL}

La importante industrialización trajo consigo algunas transformaciones sociales.

Las horas de trabajo se incrementaron considerablemente, realizando los obreros jornadas de entre 16 a 20 horas, ya que las fábricas producían ininterrumpidamente. A la vez, muchos debían realizar encargos a particulares para asegurarse unos ingresos extra.

La tradicional labor de hilado realizada en casa por las mujeres se acaba, del mismo modo que la relación del trabajador con la tierra, por falta de tiempo.

Podríamos hablar, en líneas generales, del paso de un artesano-campesino a un obrero, y de un aristócrata a un empresario tal y como lo entendemos actualmente.

\section{INVENTARIO INDUSTRIAL}

La necesidad de un inventario se planteó debido a la gran cantidad de vestigios con que nos encontramos. Del mismo modo, se nos presenta como un modo óptimo de manejar la información, pudiendo parcelarla y completarla. Es también la manera más eficiente de cotejar variables en referencia a las posibilidades de recuperación o puesta en valor. El fin es el mismo que el de un inventario a nivel regional: saber lo que qué contamos y actuar en consecuencia. Además, el mismo 
inventario y su difusión puede crear conciencia ciudadana, al igual que el turismo. ${ }^{15}$ Es decir, entendemos el patrimonio como algo que no está ahí fuera, algo dado, sino como algo que la conciencia ciudadana valora, y en su valoración, lo crea.

Se inventariaron centros productivos y edificios destacables en relación con las épocas moderna y contemporánea. Para ello, elaboramos una ficha adaptada a nuestras necesidades con aspectos varios, siendo esenciales datación y estado de conservación. Lo ideal sería poder reconstruir la historia de cada uno de los elementos individualizados. Se creó una variable de la ficha para inventariar maquinaria, aspecto que no pudo ser completado por la abrumadora cantidad de elementos a analizar.

El mayor problema que encontramos fue la dificultad de localizar los talleres, ya que los más "tradicionales" se encuentran dentro de casas sin nada que los distinga al exterior. Además, la industria textil es ligera y de por sí suele dejar pocas huellas en el paisaje.

\section{ANEXOS}

Con el fin de completar la investigación, se realizaron tres anexos. Los dos primeros analizan la ordenación territorial a partir de la inclusión de los diversos elementos - fábricas, molinos, granjas, tendido eléctrico y telefónico, etc. - en una fotografía satélite.

Los remanentes protoindustriales -molinos de linaza- se encuentran situados a lo largo del río, aprovechando la fuerza hidráulica. Los talleres textiles tradicionales aparecen en la zona más antigua del pueblo, mientras la zona industrial más moderna está emplazada al oeste, cerca de la carretera. Justo al sur de este espacio se han establecido granjas.

La industria tintórea se sitúa en la periferia al ser contaminante. El tendido eléctrico se ha renovado en 1985, mientras el telefónico conserva aún sus materiales originales de los años 50 .

El tercer anexo trata de aplicar la Arqueología de la Arquitectura al estudio del patrimonio industrial. Creemos firmemente que los edificios están vivos, son

\footnotetext{
15 GonZalez Morena en CAPEL, H. (1996) "La rehabilitación y el uso del patrimonio histórico industrial” Documents d'Anàlisi Geogràfica., n 29. pp. 19-50.
} 
historia. ${ }^{16}$ Lo que tenemos ante nuestros ojos es un aglomerado, un puzzle nunca acabado y que no siempre fue así.

Elegimos el edificio de La Comunal, antigua fábrica hoy restaurada y musealizada. Individualizamos un total de cuatro fases constructivas - cinco con la restauración- diversas que respondían seguramente a necesidades de espacio. Pueden observarse la evolución de las formas de concebir el espacio y su plasmación en la morfología final del edificio.

Pese a que los resultados han sido satisfactorios, consideramos que esta técnica habría que reservarla para edificios especiales y claramente pluriestratificados, lo cual no suele ser habitual en gran parte del patrimonio industrial. Esto lleva a que se considere esencial la labor del arquitecto ${ }^{17}$ en detrimento del arqueólogo. A menor evolución del edificio mayor papel del arquitecto.

Como resulta obvio, siempre corresponde valorar su aplicación en relación a nuestros intereses, tiempo y posibilidades ${ }^{18}$, pero en nuestro caso sería preferible ampliar el estudio a la concentración en puntos clave. No podemos entender un edificio sin lo que hay a su alrededor. ${ }^{19}$

En ocasiones contamos además con el testimonio oral y escrito, que puede hablarnos de las variaciones edilicias. Este hecho, sin embargo, no ha de ser el que nos frene a la hora de emprender un análisis arqueológico, ya que la información que nos proporciona no se halla generalmente en el testimonio escrito: condiciones de trabajo, organización de espacios, etc.

Los elementos tenidos en cuenta para la diferenciación de fases han sido principalmente los materiales, las tipologías constructivas y las zonas de conexión entre fases diversas.

\section{CONCLUSIONES}

Las conclusiones, al igual que el resto del trabajo, siguen dos "líneas" diversas. Una que se centra en la problemática tanto histórica como actual del pueblo

${ }^{16}$ AzKÁRATe, A./ GARCÍA GÓMEZ, I. (2004) "Las casas-torre bajomedievales. Análisis sistémico de un proceso de reestructuración espacial/territorial." Arqueología de la Arquitectura n³ Pp. 7-36.

17 Aguilar Civera, I. (2001) "La investigación sobre el Patrimonio Industrial. Una revisión bibliográfica” Revista de Historia, Transportes, Servicios y Telecomunicaciones $n^{\circ} 1$ pp 169-186

18 Tabales, M.A. (2002) Sistema de Análisis Arqueológico de Edificios Históricos Universidad de Sevilla, Sevilla

${ }^{19}$ AZKÁrate, A/ GARCía GómEZ, I, Vid. Supra. 
buscando soluciones. La otra que ve la investigación como una forma de experimentar, de poner a prueba, las posibilidades y la funcionalidad de la Arqueología Industrial. Trataremos de esbozar sucintamente los resultados de la primera para centrarnos en la segunda.

A nivel general se han cumplido los objetivos básicos, que dejan abierta la puerta a un estudio en mayor profundidad que esperamos emprender en un futuro. Sería importante el establecimiento de unas pautas metodológicas básicas para el tratamiento de análisis de este tipo, pero este trabajo requeriría un tratamiento individual y amplio.

El Val de San Lorenzo sufre el paso de una economía agropecuaria a una industrialización potente, que sin embargo no fue seguida por todos los productores, bien por voluntad propia, bien por falta de capitales. Esto hace que se sigan cadencias de crecimiento divergentes, que se expresan en formas de producción distintas: desde la fábrica mecanizada con todos los procesos, al telar manual en casa. Es este hecho el que "salva" al pueblo de la despoblación, al permitir, tras la crisis de los 80 , una continuidad productiva de baja intensidad basada en formas tradicionales.

Se llevó a cabo un análisis específico de las que, a nuestro parecer, eran las causas de la crisis. Expondremos aquí las posibles soluciones que se proponen, ya que en las mismas va implícito un conocimiento de las causas:

- Intento de dar a conocer e incitar a la juventud del pueblo a continuar en la tradición textil.

- Creación de una asociación de productores, como ya existió en un pasado, que evite la competencia y especialice la producción. Podría emprenderse escalonadamente, creciendo desde un acuerdo básico.

- A partir de aquí, publicitación del producto en sí, en lugar del producto de cada uno: ahondar en los valores tradicionales y naturales, la calidad de la lana, etc; valores válidos para todo productor.

- Como asociación sería más factible el apoyo institucional y la creación de una denominación de calidad "Mantas del Val".

- Analizar la situación del textil nacional e internacional.

- Modernización empresarial sin mecanización.

- Ampliación del proyecto musealizador. 
Nuestra propuesta busca una interacción entre esta hipotética asociación, el actual museo y las instituciones locales y regionales. Se trataría de aprovechar los diversos recursos del pueblo, dándolos a conocer. Se procedería a la implantación de rutas de senderismo y arqueológicas, con posibilidad de emprender excavaciones; itinerarios sobre patrimonio industrial con puertas abiertas en las fábricas y puesta en funcionamiento de industrias abandonadas... Se realizaría paralelamente un mapa digital en el que constasen estas actividades, incluyendo a los diversos productores textiles, restaurantes, etc, con los productos de cada uno. Este mapa interactivo se colgaría en la Red para una mayor difusión.

\section{LA ARQUEOLOGÍA INDUSTRIAL, ¿RENOVACIÓN O RÉMORA?}

Como ya habíamos mencionado, durante la realización del trabajo hemos tenido en cuenta las cuestiones teóricas, poniendo en cuestión la validez de los métodos de la Arqueología Industrial, sus bases, fines y técnicas. Trataremos de exponer alguna de las consideraciones que creemos necesarias tener en cuenta.

La interdisciplinariedad es un aspecto esencial. En ciertas disciplinas la cuestión es motivo de tensiones, derivadas de visiones cerradas y unipolares ante problemas similares. En Arqueología de la Arquitectura la relación con el arquitecto merece siempre trato especial ${ }^{20}$ y lo mismo ocurre con los ingenieros en el caso de la minería romana. ${ }^{21}$ En el caso de la Arqueología Industrial la cuestión es aún más espinosa, ya que la gran diversidad de paradigmas especializados estudiados requiere diversas colaboraciones: arquitectos, geógrafos, ingenieros industriales, de caminos, de minas... En nuestro caso hemos contactado con un ingeniero industrial y un arquitecto. Creemos firmemente que la relación puede ser fructífera siempre que se establezcan unos marcos de acción claramente delimitados. El arqueólogo industrial no puede manejar todo lo que estudia, pero le compete saber a quien recurrir para abarcarlo.

Sin embargo, creemos que las labores de recopilación de testimonios documentales y orales puede y debe recaer en manos del arqueólogo, a no ser que el proyecto sea de envergadura tal que estos aspectos requieran un tratamiento específico. Esto le permitirá establecer relaciones con el registro arqueológico. La ausencia de una licenciatura específica en Arqueología en nuestro país hace que el arqueólogo se suela centrar durante sus estudios en estos menesteres, por lo que

20 Tabales, M. A. Vd Supra. También: Caballero Zoreda, L. (2004) "Una experiencia en Arqueología de la Arquitectura" Arqueología de la Arquitectura no 3, pp 127-142.

${ }^{21}$ Nuevos Elementos de Ingeniería Romana, (2006) III Congreso de las Obras Públicas Romanas, Astorga. 
está perfectamente capacitado. De este modo, Arqueología e Historia quedan ligadas íntimamente. Sólo encontramos sentido a la Arqueología de investigación si trata de resolver problemas históricos, aunque lo haga con unos métodos y técnicas propios, que son los que le confieren su autonomía como ciencia.

La completa asunción de esta forma de hibridación entre Historia y Arqueología llevará tiempo y traerá no pocos problemas, como ya ocurrió con la Arqueología Medieval. Suele alegarse que la abundancia de documentos de todo tipo en época contemporánea hace innecesaria la intervención arqueológica. Pero debemos recordar que la Arqueología nació para responder preguntas y llenar lagunas de la Historia. Así ocurre si comparamos la centenaria Arqueología Clásica, con abundancia de documentos para la época estudiada, con una Arqueología de la Alta Edad Media que carece de ellos y es en cambio muy joven.

Creemos que el concepto de "cultura material" puede servir como elemento integrador entre ambas ciencias, si bien es cierto que de tan manido como está, en ocasiones llega a ser a la vez todo y nada. ${ }^{22}$

Se presenta como un punto esencial el replanteamiento de la noción de patrimonio. El concepto de patrimonio, al igual que el de arte, ha de pasar necesariamente una actualización, sufriendo posiblemente una crisis de identidad como sufrió aquel, que, naturalmente, ha de ser superada para alcanzar una idea más abierta y comprensiva.

Así, este cambio conceptual aparece como algo completamente esencial para asentar los cimientos de la Arqueología Industrial como ciencia. Patrimonio no es lo "antiguo" ni lo "bello", sino aquello que dice algo de nuestro pasado, aquello que puede ser objeto de estudio como bien histórico, algo con lo que podamos identificarnos. Como se mencionó un poco más arriba el patrimonio se crea y modifica al ritmo de las mentalidades colectivas, siendo un buen ejemplo la diferenciación social establecida entre lo "viejo" y lo "antiguo". ${ }^{23}$

La ley de patrimonio histórico español no protege en absoluto estos vestigios, trazando una frontera imaginaria en los 100 años. $^{24}$ Podrían protegerse amparándose en que son susceptibles de estudio arqueológico. ${ }^{25}$

${ }^{22}$ MALPICA, A. (1993) "Historia y Arqueología Medievales: un debate que continúa". Problemas actuales de la Historia. Salamanca, , pp. 29-47.

${ }^{23}$ CANO SANChíz, J.M. (2006) "Arqueología Industrial y Patrimonio: Nuevas reflexiones a partir del caso cordobés” Arte, Arqueología e Historia, n 13, Córdoba, pp 156-162.

${ }^{24}$ Ley 16/1985 de Patrimonio Histórico Español. 
No nos parece lógico dejar desprotegidos unos restos que, debido a la constante aceleración de la evolución científico-técnica, forman ya parte de otra época. Las nuevas generaciones ven la Guerra Civil como algo muy lejano, y van sólo 70 años.

Del mismo modo, no estamos de acuerdo con el posicionamiento de esperar a la fosilización u olvido de estos remanentes, arriesgándonos a que no se conserven, para justificar su estudio arqueológico. ${ }^{26}$ ¿Debemos esperar a la destrucción y ruina para iniciar la excavación y reconstrucción? ${ }^{27}$

No entendemos las tendencias que tienden a vincular este patrimonio como perteneciente al pueblo, o apreciado por él, buscando potenciar su valor patrimonial por haber sido muy utilizados. ${ }^{28}$ La fábrica y la mina pertenecen a las clases al altas del mismo modo que una villa romana o un castillo; quienes trabajan en ellas no lo hacen de buena gana. De hecho, quien tuvo relación con una industria, desvinculándose posteriormente, suele mantener una cierta animadversión hacia ella.

Por supuesto, hay que ser selectivos con este patrimonio y no incitar a una fiebre conservacionista. Debemos elegir lo singular, lo que representa un tipo, o lo que tenga un valor artístico o histórico ${ }^{29}$. En ocasiones también tenemos que contar con que ciertos elementos poseen un valor especial creado por los habitantes con los que se relaciona.

Lo ideal es una musealización de los vestigios, que cuente con el entorno y se hibride con él, ejerciendo de centro neurálgico y encargándose de labores de concienciación, fomento de actividades relacionadas, conservación de otros restos, etc. Al ser esto harto difícil dada la abundancia de material, abogamos por una reutilización procurando mantener una armonía entre bienes muebles e inmuebles. Dentro de este marco general, las vías posibles para la puesta en valor son

${ }^{25}$ CANo SANChíz, J.M. (2005) "Mecanismos de gestión, administración y musealización." Arte, Arqueología e Historia, $\mathrm{n}^{\circ}$ 12, Córdoba. Pp 111-116.

${ }^{26}$ ReYEs TÉLlEZ, F. (2004) "El patrimonio arqueológico industrial en la ciudad histórica." Anales de Arqueología cordobesa, $\mathrm{n}^{\circ}$ 15, pp. 83-99.

27 Barral i Altet, X. (1989) "Arqueología Industrial o Arqueología del Mundo moderno y Contemporáneo" A distancia, $\mathrm{n}^{\circ}$ 1, pp. 36-42.

${ }^{28}$ CASANELles RAHOLA, Eusebi. (1996) "Recuperación y uso del patrimonio industrial." Revista de Cultura y Ciencias Sociales. No8 Segunda época.

${ }^{29}$ Idem. 
infinitas $^{30}$. Cada situación se valorará en su especifidad, siempre compleja: posibilidades financieras privadas o públicas, propiedad de los vestigios, etc. La situación es muy distinta a nivel rural donde los estudios escasean, y a nivel urbano, donde se ha alcanzado una mayor profundidad. Sería de interés la exposición de una metodología de trabajo para entornos rurales como el que nos ocupa.

Sus posibilidades como atractivo turístico no han pasado tampoco desapercibidas, desde perspectivas tan distintas como la del turismo ${ }^{31}$ o la de la ingeniería industrial. ${ }^{32}$

No abordaremos aquí los problemas de la relación ente Arqueología de Investigación y de Gestión, y, a fin de cuentas, economía-cultura e interés públicoprivado. Este tema merecería ser objeto de un análisis individualizado.

En definitiva la Arqueología Industrial es, o se ha convertido, en el estudio y conservación de los restos industriales. ${ }^{33}$ Esta definición tan amplia abre un abanico inmenso de interpretaciones. La Arqueología Industrial debería ser una disciplina que se encargase del análisis de fases históricas en las que la industria jugase un papel destacable como motor del desarrollo socio-económico, a través de una visión dilatada y abierta del periodo y su paisaje y no sólo fijándonos en la ruina industrial. Estas fases seguirán cadencias diversas según zonas dejándonos unos vestigios divergentes, a los que debemos adaptarnos. A la vez, y según las exigencias de la investigación, convendría tener en cuenta la situación patrimonial y las posibilidades de regeneración y puesta en valor del lugar investigado.

Es cierto que las intervenciones arqueológicas modernas-contemporáneas en muchos casos se orientan por un conocimiento histórico previo y en función a la respuesta de preguntas precisas. ${ }^{34}$

${ }^{30}$ ID. y AGUilar CiverA, I. (2001) "La investigación sobre el Patrimonio Industrial. Una revisión bibliográfica" Revista de Historia, Transportes, Servicios y Telecomunicaciones $\mathrm{n}^{\circ}$ 1, pp 169-186. Especial atención a este respecto merecen los trabajos de Horacio Capel (ver nota 7)

31 PEÑAlVER TORRES, M.T. (2002) "La arquitectura industral: patrimonio histórico y utilización como recurso turístico." Cuadernos de turismo no 10, pp. 155-166.

32 Feliú-Torras, A. (2007) "La importancia de recuperar la memoria y el Patrimonio Industrial en España”, Dyna, Vol. 82 n 4. pp. 64-65.

${ }^{33}$ Hudson en Aguilar Civera. Vid. Supra.

${ }^{34}$ Barral i Altet, X. Vid. Supra. 
Es importante alejarse de visiones tecnicistas, y de la creación de límites ficticios en cuanto al ámbito y alcance de la investigación. La Arqueología trata de explicar procesos, y con ello ha roto las tradicionales divisiones de la Historia, que tan perjudiciales han sido para el conocimiento científico. Si apoyasemos alguno de los diversos límites finales propuestos para el ámbito de estudio de lo industrial, como por ejemplo el primer lanzamiento espacial desde cabo Cañaveral en $1953^{35}$, o las restricciones en el estudio de elementos en uso ${ }^{36}$, el presente estudio no existiría.( En Val de San Lorenzo la industrialización se desarrolla en los últimos 80 años. Estudiamos en ella talleres artesanales en funcionamiento, a la vez que imponentes fábricas mecanizadas ya calificables como ruina.) Y, en caso de pretender crear límites, convendría fijarnos en transformaciones inherentes al propio sistema. Así por ejemplo la revolución informática o la cibernética, y planteando fechas concretas, el viernes Malboro de 1993 que puso en entredicho el poder de la publicidad y la confianza en las marcas. ${ }^{37}$

Omitimos intencionadamente en la definición la restricción de la Arqueología Industrial al mundo capitalista, tan universalmente aceptada. ${ }^{38} \mathrm{Y}$ es que creemos que la potente industrialización del Bloque del Este también merece ser estudiada; más teniendo en cuenta que ya analizaban y valoraban su patrimonio antes que en Occidente. ${ }^{39}$

Otro de los mayores problemas a los que se enfrenta la Arqueología Industrial es la enorme dificultad de equilibrar su faceta científica con la tecnológica. La tecnología pone a disposición de la sociedad los conocimientos científicos. La Medicina, la Ingeniería, el Derecho, son tecnologías que se sirven de ciencias como la Biología, la Física o la Historia. Es decir, hasta donde queremos investigar y cuando comenzamos a poner en valor. Inclinarse excesivamente hacia cualquiera de los dos extremos resultaría nefasto para la disciplina y haría que perdiese su

35 JiMÉNEZ BARRIENTOS (2001) en CANO SANCHÍZ, J. M. (2004) “Arqueología Industrial: claves para la comprensión de una nueva forma de hacer Arqueología." Arte, Arqueología e Historia, no 11. Córdoba.

${ }^{36}$ REYES TÉLLEZ, F. (2004) "El patrimonio arqueológico industrial en la ciudad histórica." Anales de Arqueología cordobesa, $\mathrm{n}^{\circ}$ 15, pp. 83-99.

${ }^{37}$ Klein, N. (2007) No Logo: El poder de las marcas. Paidos Ibérica, Barcelona.

38 Carandini en Aguilar Civera, I. (2001) "La investigación sobre el Patrimonio Industrial. Una revisión bibliográfica" Revista de Historia, Transportes, Servicios y Telecomunicaciones $\mathrm{n}^{\mathrm{o}} 1$, pp 169-186.

39 MARTínez, J. M. y ClosA, F. (1999) "L'arqueologia industrial: una visió a la fi del millenni." Revista de Arqueología de Ponent, ${ }^{\circ} 9$. 
valor más importante: la capacidad de tender puentes entre el conocimiento científico y la sociedad; gracias a su acaparamiento del uso de tecnologías como la Museología y el aprovechamiento de las ventajas de sus aplicaciones técnicas.

Trasponiendo esto al Val de San Lorenzo, la pregunta sería, ¿hasta qué punto queremos conocer la evolución de las diversas industrias, pudiendo comenzar a beneficiarnos de los recursos producidos por una eficiente puesta en valor? Como ya se mencionó al principio, la ciencia no da respuesta a estas preguntas, sino que es la sociedad a través de sus instituciones la que decide qué camino desea seguir.

Por otro lado, afirmamos la necesidad de establecer una línea de separación entre Arqueología Industrial y Arqueología Contemporánea, ya que al contrario que otros autores ${ }^{40}$, no las consideramos equiparables. La Arqueología Industrial no ha sido capaz - a diferencia de la Arqueología Medieval - de aprender de los errores de sus hermanas en el pasado ${ }^{41}$ pasando a designar los lugares y artefactos que estudia en lugar de el cómo los estudia. ${ }^{42} \mathrm{La}$ incluiríamos dentro de una Arqueología Contemporánea, como una especie de Castellología en el mundo medieval. Está más relacionada con la puesta en valor y con el mundo de la técnica, intrínsecamente vinculada al concepto kantiano de una sociedad en constante progreso ${ }^{43}$. Los intentos de ampliar el ámbito de estudio teniendo en cuenta el paisaje, relaciones de producción, cultura, medios de comunicación, etc ${ }^{44}$, pese a ser encomiables, siguen tomando como punto de referencia el conjunto industrial. Es cierto que, al igual que los castillos en la Edad Media, pueden ser centros nodales y hacer girar en su órbita gran número de procesos claves para comprender una época. También es lógica la puesta en valor de estos centros en lugar de otros de carácter periférico dado su mayor atractivo; mejor conservar una fábrica textil que un lavadero de lana.

${ }^{40}$ OrfiLA, M y CAU, M.A. (2002) “Miret, naranja y limón con piel de cristal: Arqueología, cultura material e Historia Contemporánea" Mayurqa, no 28 pp. 111-127; Barral i Altet, X. Vd. Supra.

41 CARANDINI EN Gutierrez Lloret, S. (1995) Fuentes materiales e historia contemporánea : unas reflexiones sobre la arqueología industrial desde la arqueología Alicante, pp 51-60.

42 Newell en GutierReZ LlORET, S. Idem.

43 Castro Morales, F. (2001) "Memoria, ocio y cultura: nuevos usos en España para el patrimonio industrial." Preservación de la Arquitectura Industrial en Iberoamérica y España, Instituto Andaluz del Patrimonio Histórico. pp. 204-212.

44 ESPERICUETA, M. (2004) "Nuevas tendencias en la investigación histórica: algunas propuestas sobre Arqueología Industrial" Historia digital n6,; Forner, S., Santacreu, J.M., Santiago, A. (1991) "Arqueología Industrial (notas para un debate)" Málaga. 
Pero una Arqueología Contemporánea rigurosa ha de plantearse investigaciones totalizadoras que intenten valorar en su justa medida cada uno de los patrones analizados, preguntándose qué información puede extraer de cada uno de ellos para conocer los entresijos de un sistema socioeconómico complejo.

¿Por qué no una Arqueología Agraria Contemporánea? Conocer la agricultura de los últimos dos siglos y valorar las consecuencias de una concentración parcelaria. Evaluar la implantación de la industria, qué cambió en el paisaje y las alteraciones en las formas de vida de una comunidad. Cómo, en conexión con ella, comenzó a bosquejarse el trazado de una compleja red de comunicaciones que expandió los horizontes de millones de personas. Cómo, sin variar esta estructura, una Guerra Civil transforma todas las relaciones socio-económicas, legándonos unos remanentes que siempre tienen su por qué. Cómo, finalmente, todo esto es marginado y olvidado por una sociedad que ya lo ve como de otra época pero que sigue sin prestarle la atención que se merece.

\section{BIBLIOGRAFÍA}

Alonso González, P. (2007) Arqueología Industrial en el Val de San Lorenzo León, Nueva Comunicación.

Alvarez, M. A. (edic), (2001) Arqueología Industrial, Patrimonio y Turismo Cultural, Gijón.

ANDRÉS Nistal, P. (1994) El sector industrial en la ciudad de León y su entorno" León, Universidad de León.

Balboa de Paz, J. A. (2005) "La térmica de la Minero Siderúrgica de Ponferrada." Bergidum, $\mathrm{n}^{\circ}$ 4, , p. 10-16.

Balboa De PAZ, J.A. (2006) El Patrimonio Industrial de la provincia de León León, Instituto Leonés de Cultura,.

BALLART, J. (1997) El patrimonio histórico y arqueológico: valor y uso Barcelona.

BENITO DEL POZO, P. (Dir.). (2006) Suelo industrial y territorio en León. León, Universidad de León.

CAPEL, H (1996) "La rehabilitación y el uso del patrimonio histórico industrial”. Document d'Análisi Geográfica, nº 29, pp 19-50.

CARANDINI, A. "Arqueología Industrial”, en Rivista di Storia dell'Arte, VII, Roma, 1978.

CASANelles i Rahola, E. (1997) "Patrimonio Industrial y museológico en Cataluña", Boletín del Instituto Andaluz del Patrimonio Histórico Núm. 21, p. 125-129

ForNER, S. y SANTECRE, J. M. (eds.), (1989) Jornadas sobre teoría y métodos de Arqueología Industrial, Alcoy, Departamento de Humanidades Contemporáneas, Universidad de Alicante.

ForNer, S. (1991) Arqueología Industrial. Concepto, teoría y métodos, Arqueología Industrial (notas para un debate) Málaga.

Francovich, R. y PARENTI, R. (1987) Archeologia e restauro dei monumenti, Florencia. 
GiMÉNEZ, F., (1995) "Los sistemas de información geográfica aplicados al patrimonio. El SinambA: una aplicación medioambiental", en I Jornadas sobre Catalogación del Patrimonio Histórico, Sevilla, p. 5.

GonzÁlez-Morena, A. (1995) Patrimonio arquitéctónico: lo que el viento no se llevó, Actas de las I Jornadas sobre Catalogación del Patrimonio Histórico. Hacia una integración interdisciplinar, Sevilla, Instituto Andaluz del Patrimonio Histórico.

HEREDIA, R. (1971) Arquitectura y Urbanismo industrial, Madrid.

HudSON, K. (1976) The Archaeology of industry, Londres.

LÓPEZ TRIGAL, L. (Coord), (1996) La disponibilidad de recursos y el desarrollo industrial leonés. Reunión del Grupo de Geografía Industrial. León, Universidad de León.

Palmer, M. y NeAverson, M., (1998) Industrial Archaelogy, Principles and practice London, Routledge.

PuCHE, O. Y MAZADIEGO, L.F. (1997). "Conservación del patrimonio minero metalúrgico español: actuaciones recientes y propuestas" Tecnoambiente, 69,. Madrid, TIASA. Madrid, pp. 39-43.

RepresA, M. F. y HelguerA, J. (1997) "El patrimonio industrial de Castilla y León: iniciativas para su estudio y conservación.” Estudios Bercianos, , nº 23, p. 79-103.

RodRíGUEZ LAGO, J. (Coordinador) (1994) La empresa industrial de la provincia de León. León León, Universidad de León.

SEDPGYM (1996-1999). Noticias y comentarios sobre el patrimonio geológico y minero. Boletines 7, 8, 13, 14. Madrid. 
I. Cambios de hábitat en Val de San Lorenzo. Google Maps

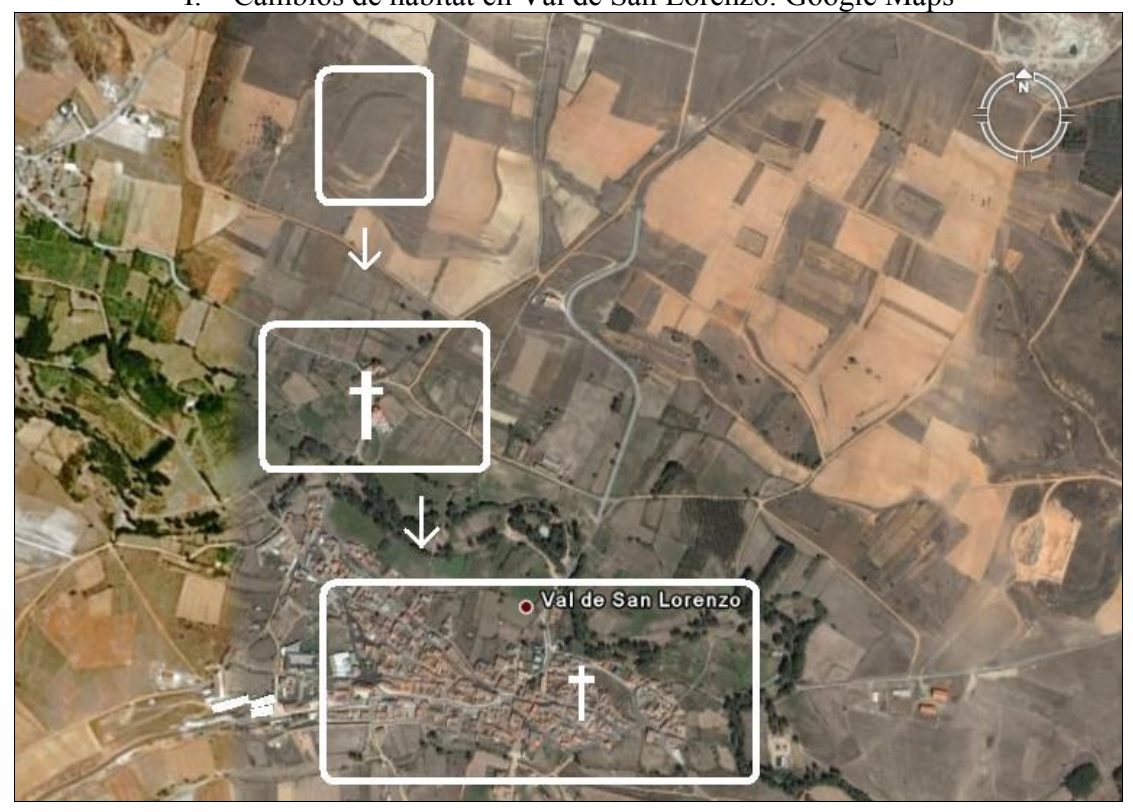

II. Ficha modelo del inventario realizado en Val de San Lorenzo.

\begin{tabular}{|c|c|c|c|}
\hline & & $\begin{array}{l}\text { NOMBRE } \\
\text { LIMASA } \\
\text { NÚMERO } \\
\quad 9\end{array}$ & $\underset{9}{\text { FICHA }}$ \\
\hline $\begin{array}{l}\text { DESCRIPCIÓN } \\
\text { GENERAL }\end{array}$ & \multicolumn{3}{|c|}{$\begin{array}{l}\text { Construcción de gran tamaño, compleja, en torno a un } \\
\text { edificio rectangular central con un patio interior, en } \\
\text { ladrillo, caracterizada por su gran chimenea. }\end{array}$} \\
\hline Trabajo desempeñado & Datación & \multicolumn{2}{|c|}{ Activo/ Inactivo } \\
\hline $\begin{array}{c}\text { Fábrica Textil, con todos } \\
\text { los procesos }\end{array}$ & 1952 & \multicolumn{2}{|c|}{ Activa a rendimientos mínimos } \\
\hline \multicolumn{2}{|c|}{ Conservación externa } & \multicolumn{2}{|c|}{ Conservación interna } \\
\hline \multicolumn{2}{|c|}{ Buena } & \multicolumn{2}{|c|}{ Buena, conserva la maquinaria } \\
\hline \multicolumn{4}{|l|}{ Observaciones } \\
\hline \multicolumn{4}{|c|}{$\begin{array}{l}\text { Es la fábrica de mayor tamaño del pueblo, con un perimetro de } 300 \text { metros y varias } \\
\text { naves. } \\
\text { Su nombre completo es Lanera Industrial Maragata S.A. } \\
\text { Posee secaderos de lana en su entorno. (Fot. 9C) }\end{array}$} \\
\hline
\end{tabular}


III. Diversas fases constructivas del edificio de La Comunal. Google Maps..
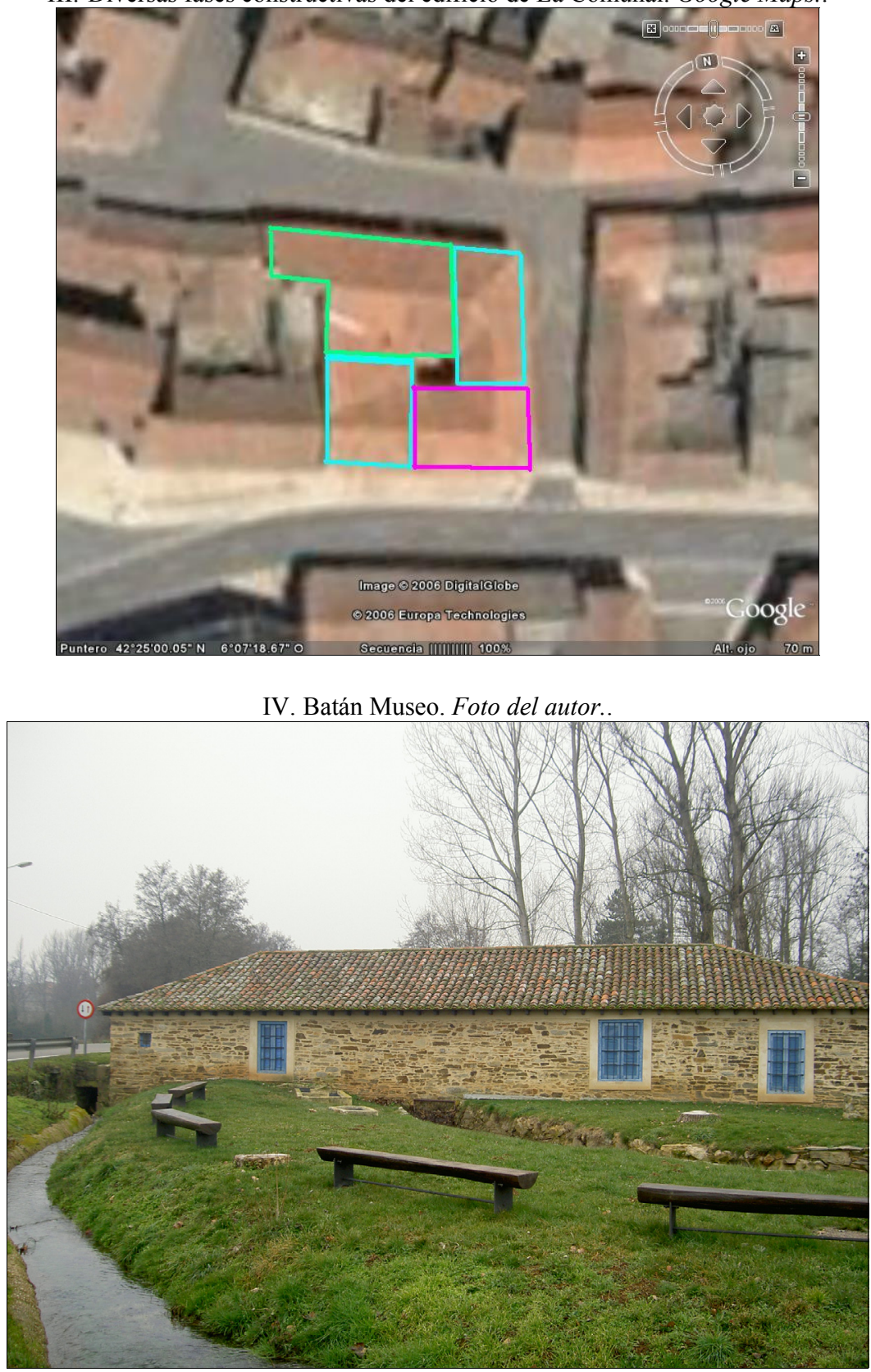